\title{
Proceeding
}

10th INSHS International Christmas Sport Scientific Conference, 4-5 December 2015. International Network of Sport and Health

Science. Szombathely, Hungary

\section{Descriptive shot analysis in basketball}

\author{
GAETANO RAIOLA ${ }^{1}$,TIZIANA D'ISANTO ${ }^{2}$ \\ 1 University of Parthenope, Naples, Italy \\ 2 University of Salerno, Salerno, Italy
}

\begin{abstract}
This paper tries to clarify from specific points of descriptive view, physical, technical, tactical and from that learning model, those that are the fundamental elements of the shot to basket, in order to optimize the setting and specific preparation. The physical learning is the basis of the performance, that is the skills depends from qualitative aspect. The shot is a fundamental attack in basketball, offers many points to be analyzed from technical point of view that the qualitative control model point of view, this article will try to do it on both aspect, trying to provide some elements technical and descriptive to whom refer and the description of the executive model elements characterizing the execution of the shot at basket. The aim is suggesting some technical elements to which to refer and the description of the executive model elements that characterize the execution of the shooting at basket, to improve the whole process of teaching and learning. Key words: EXECUTIVE MODEL, PERFORMANCE, TECHNICAL SKILL.
\end{abstract}

\footnotetext{
Corresponding author. via Berenice 11, Napoli, Italy

E-mail: raiolagaetano@libero.it

10th INSHS International Christmas Sport Scientific Conference, 4-5 December 2015. International Network of Sport and Health Science. Szombathely, Hungary.

JOURNAL OF HUMAN SPORT \& EXERCISE ISSN 1988-5202

(c) Faculty of Education. University of Alicante

doi:10.14198/jhse.2016.11.Proc1.18
} 


\section{INTRODUCTION}

In the game of basketball the shot is the main action of the attacker; in fact, it is the instrument by which players translate them into points the offensive actions of own team. In this regard, Gamba said: "you become good shooters, are not born. I doubt there has ever been a great shooter that he would not have needed to endless hours of training to develop its effectiveness "(Gamba, 1995).

For this reason, to become a good player one must learn to cure this fundamental technical. Knowing how to pull with high percentage of realization means, essentially, give enormous guarantees of victory to own team, without underestimating the psychological aspect positive on the one hand, esteem and gratification of the team towards the player and on the other the negative impact which infuses on the opponents, of concern and insecurity in respect of a great shooter.

Having one or more players in field that they can realize high percentages of shots, brings a significant advantage at their team and disfavoring therefore, tactically and psychologically, the opponents complicating the them defensive duties. The coaches have the need to build players capable of minimizing the reaction time; therefore, in practice, each player must be able to perceive by intuition what his opponent is going to do and to take advantage; this advantage is then maintained and concretized in a positive result, such as achieve a shot at basket (Raiola, 2011, 2014, 2015ab, Raiola,Tafuri, 2015, Raiola et al, 2014, 2015).

The qualities required of a good shooter are: body balance in static and dynamic situations, concentration and attention of the detail, coordination, sensitivity and the correct execution of a parabola. The knowledge, sometimes superficial, of physical systems, the musculature and related elements, certainly allows to qualify the intervention of the proposition of the field work in a more targeted as well as scientific (Izzo et al, 2015). In developmental age, these aspects have the significative relevance in learning of skill (D'anna et al, 2015). The aim is suggesting some technical elements to which to refer and the description of the executive model elements that characterize the execution of the shooting at basket, to improve the whole process of teaching and learning.

\section{MATERIAL AND METHODS}

Descriptive approach is the basis of method investigation about specific aspects of technical execution of shot. Also in futsal, waterpolo and swimming (Napolitano et al, 2013, Polidoro et al, 2013, Tursi et al, 2013) used to utilize systematic observation to evaluate skills.

Each player will have a shooting executive entirely subjective, since it varies in relation to its heritage conditional and coordinative, at the its stature, at the its ability to establish the starting point of the shot, at the type of defender (height and aggression) and at the away from the basket.

A good formulation of the shooting must take into account of the alignment: index, wrist, elbow, tip toes pointing to the basket. The elbow should stay close to your body in a natural way, it is possible that some players tend to "open" the outwards elbow. If it is done in a natural way, it would be best not to correct it this, especially if then the shooting mechanics is fluid and release takes place properly.

The arm and hand are parts of the body directly concerned with the thrust and direction of the ball, and they are also those parts who commit more errors and affect the final quality of the shot. In the carry out the shot 
the upper limb begins, usually from a position partial homers in abduction and external rotation that, in the final phase of the movement, is in full extension and in anterior-posterior position.

As regards the hand, the intervention of the palm during the pushing can interfere negatively removing the necessary sensitivity on the ball, having as a result little rotation of the ball. Finally, the intervention of the finger middle and of the index on the ball, in fact, are the fingers that leave for last ball, both should be turned outwards and downwards, otherwise the ball will not acquires an optimal rotation and the right direction. Finally, the location and the push of the lower limbs, however, should not be neglected, since the shot begin from the feet; In fact, the indication that you can give is try to have a position of feet wide about the shoulder width, with your foot corresponding at the hand that pulling of about half a foot ahead of the other.

\section{RESULTS}

An entry angle at $90^{\circ}$, from a distance of about 5 meters, it is impossible from obtain, as it would require a considerable output speed beyond the capability of an athlete who uses any shot orthodox. Also, there is to consider the effect that produce small errors of the exit angle on the distance of the shot are proportional, and these deviate the ball farther and farther away from the center of the basket; therefore, while a large angle shot is desirable because it leads to a high entrance angle, it is less desirable of smaller angles for what concerns the precision.

The best angle of shot produces trajectories with a bow rather low rather than medium or high. And you need to understand what are the variables that affect performance with purpose to improve it (Picasso B., 2012). The equation $E= \pm(0.2286$ sen $a-r) \mathrm{cm}$., Allows us to calculate the chance that the ball has to go on the vertical axis of the basket (Tab. 1), where:

$r=$ radius of the ball

$\mathbf{E}=$ error margin

$\alpha=$ angle of entry

Table 1. Angle of entry and the margin of error

\section{$\alpha$, angle of entry $\quad E$, margin for error in $\mathrm{cm}$., respect to the center of the ball}

$\begin{array}{ll}90^{\circ} & \pm 10,54 \\ 80^{\circ} & \pm 10,18 \\ 70^{\circ} & \pm 9,14 \\ 60^{\circ} & \pm 7,38 \\ 50^{\circ} & \pm 5,18 \\ 40^{\circ} & \pm 2,36 \\ 32^{\circ} \text { e } 39^{\prime} & \pm 0,00\end{array}$


Practical experience and the results obtained also the aiming point should not be overlooked by the coaches; so we should provide as aiming point the far side of the circle than the firer, because if the ball hits the ring of the basket, a ball spin counterclockwise will help the same to enter the basket. In the case, instead, of a short shot you can have a margin of error of about $22 \mathrm{~cm}$., Since this difference that there is between the ball, having a diameter of about $24 \mathrm{~cm}$., And the inner circumference of the ring the basket of $45 \mathrm{~cm}$., there is the possibility that the ball bouncing on the board and enters the basket. Finally, if the ball at the end of the parable hits the backboard or the ring of the basket the factors leading to the entrance at basket (established that the mass of the two bodies and their return coefficient are constant) are represented by:

- Point of contact of the ball.

- Its speed at the moment of contact.

- From the rotation of the ball.

\section{Analysis of the shot}

The shot from the biomechanical point of view interests the lower limb (foot, leg and thigh), the trunk (stabilizer musculature of the body in flight) and the upper limb (hand, forearm and arm). The main muscle groups of the upper limb that intervenes during the action of the shot are:

a. Flexors forearm: brachial

b. Flexors of the arm: anterior deltoid, grand pectorals (upper fibers), and biceps coracobrachialis

c. Extensor forearm: triceps

d. Pronator of the forearm: pronator tires and square

e. Extensors of the hand: extensor the radial and ulnar, radial extensor short and extensor ulnar

f. flexors of the hand: radial and ulnar

g. Flexors of the last four fingers of the hand: lumbrical, interosseous, flexor superficial and deep of the fingers.

Until the player does not bend on the legs, the muscles perform an isometric work and the force used is minimal. The muscular work, during the step of bending, is concentric and the force used increases. After the bending, when the player stretch the lower limbs, the muscles are released slightly, the pressure on the ground is lower and consequently also the force used is reduced. The player locks the movement of folding at the moment of the shot, the muscles perform an eccentric work and the force applied on the ground increases. During the phase release of the ball from the hand, the muscles of the lower limb are concentrically contracts, pushing strong on the ground of play and thereby increasing the force used (Tab. 2).

Table 2. Muscle work during the shot

Phase of the shot

Type of muscular work

Force used

Before the beginning

Isometric

Minimum

Bending of the lower limbs

Concentric

Increases

Extension of the lower limbs

Slight relaxation

Decreases

Release the ball

Concentric

Elevated 


\section{DISCUSSION}

Over time, the technical act of the shot is fundamental individual that has had more evolutions. There is been, in fact, a gradual introduction of new shooting types (stationary, in elevation and in suspension) and changes to the regulation (24 seconds, introduction of the 3-point first and then from the $6.25 \mathrm{mt}$ to $6.75 \mathrm{mt}$ ). This has produced some significant results:

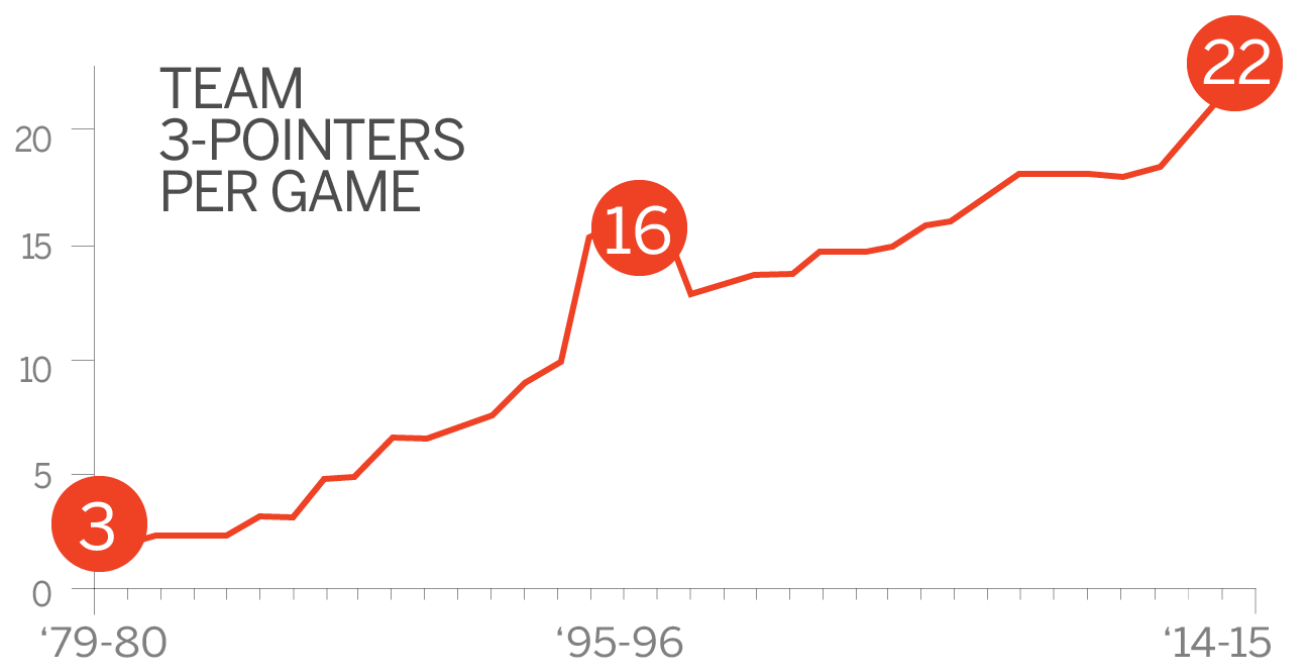

Figure 1. Steady rise in 3-point attempts since its introduction in the 1979-80 season

- You pull more and with high percentages compared to the early 2000s.

- There has been a speeding up of the actions of game.

- There was an increase of the spectacle.

The ability of shot is related to the objective of performance of the sport, then it can refer to the horizontal distance, at the flight time, at the precision or speed of movement (Scrimaglio, Di Giminiani, 2013). The shot offers several ideas to be analyzed, both in terms of technical sport that from the standpoint of biomechanics.

Analyzing various shots from different positions and distances, the trajectories realized by the ball, can be assimilated as at the model of parabolic curve, depending on the angle of departure of the ball (Mondoni, 2002). One of the sports where you can notice this parabolic motion is basketball, since the player must try to pull a ball in a basket placed higher than him and therefore the trajectory of the ball you will get from the union of two movement, from that with speed uniform oblique, for picking up the ball, and uniformly accelerated down for force of gravity (Fig. 2). 


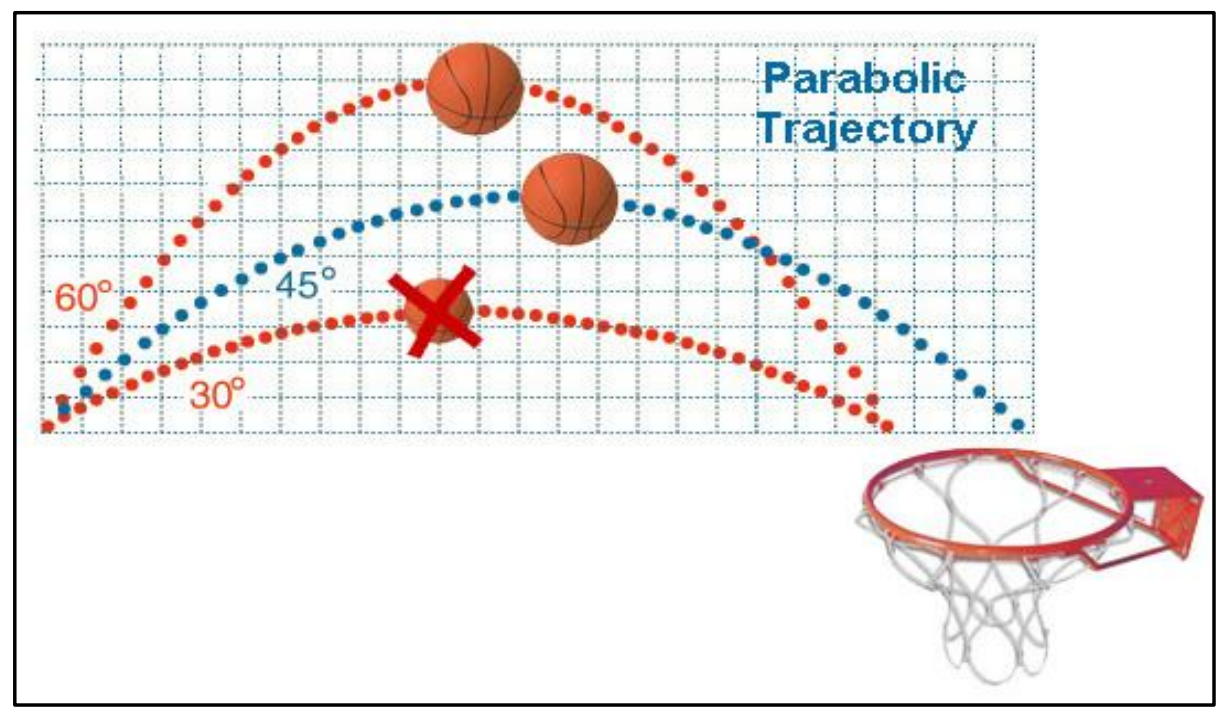

Figure 2. Trajectory of the ball with a shot to basket

The technical factors that govern a shot, apart from the force impressed, are:

1- The starting height of the ball.

2- The air resistance.

3- The release rate of the ball.

4- The exit angle of the ball.

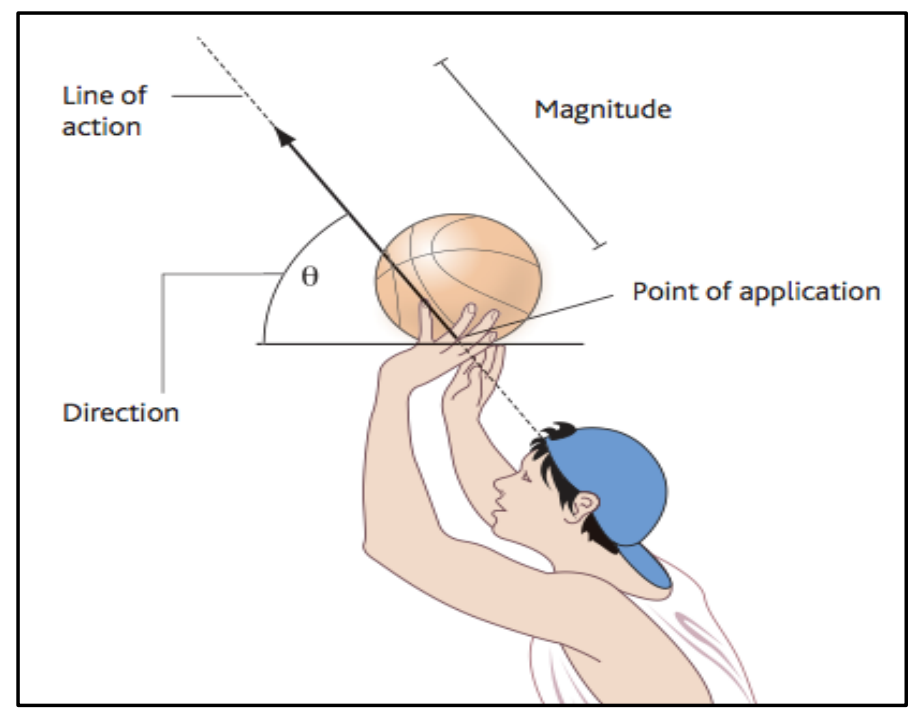

Figure 3. The four properties of force (Hede, Russell, \& Weatherby, 2011)

The stationary ball in the hands of the shooter will not have any moment, due to its lack in velocity, but it will still have inertia as a force will have to be applied to change its state of motion (Blazevich, 2007). In order to change the ball state of motion force beginning at the shooter's feet and ending and working its way up the body to the fingertips will have to be applied to direct the ball at the intended target. Research conducted by Rojas, Cepero, Oña, and Gutierrez (2000) has suggested that the velocity that the ball is released at does not change dramatically when comparing shooting a jump shot with pressure and without defensive pressure. Rather than producing more velocity into the shot itself, a player is therefore more likely to implement other kinetic changes in order to overcome the pressure placed on the shot by a defensive player. 
The height of outlet of the ball is determined by the morphology of the player and from the type of shot used in relation to the defender and to the distance from the basket. The air resistance appears to be irrelevant on the trajectory of the ball. Dependence on these influencing factors (the height of outlet of the ball, the combination of the rate of release and the exit angle of the ball) are related to:
A. At the distance of the shot
B. At caliber of the defender
C. At the corner of entry, with which the ball should enter the basket to allow the maximum of the tolerance or space for the error.

A. The rate of release and the exit angle are interdependent, while the distance of the shot directly influences the rate of release, which increases on account of distance, and indirectly the angle of release. The accuracy of the shot varies with distance, as even small deviations become more evident in relation to the residence time of the ball in the air.

B. The physical structure, the ability to jump, the position and the technique of the defender all have a relationship of influence on the speed and angle of exit of the ball that must be such as to allow it to pass over the extent of the intervention of the defender.

C. The role of the angle of entry is rather complex. With an entry angle of $90^{\circ}$ the basket it is presented to the ball in all its width equal to $45 \mathrm{~cm}$., therefore with the maximum margin of error as possible.

\section{CONCLUSIONS}

In light of the above, we believe we have provided some technical-scientific elements, to which doing refer in practice of sport, not only in terms of scientific and theoretical study of the subject, but also as a tool for verification of work programs always more finalized to the qualification and to the specificity of the training proposal , connecting more and more their own system of work with elements more and more specific and directly related at fundamental of the shot, abandoning a training method based on the generic, this aspect not is longer sustainable in the modern competitive sports activities. At last, is a good idea to remember that the highest level of coordination is one in which the player, in addition to successfully perform the gesture, keeps the possibility to modify and adapt to the "real situation" while maintaining the effectiveness (Altavilla, Raiola, 2014,2015). Learning, however, only reached a level cognitive abstract stays away from the real context and direct experience (Altavilla et al, 2014ab, Gaetano et al, 2015ab).

\section{REFERENCES}

1. Altavilla, G., Raiola G. (2015). Sports game tactic in basketball, Sport Science, 8(1).

2. Altavilla, G., Raiola, G. (2014. Global vision to understand the game situations in modern basketball. Journal of Physical Education and Sport, 14(4).

3. Altavilla, G., Tafuri, D., Raiola, G. (2014a). Influence of sports on the control of static balance in physical education at school. Journal of Physical Education and Sport, 14(3).

4. Altavilla G., Tafuri D., Raiola, G. (2014b). Some aspects on teaching and learning by physical activity. Sport Science, 7(1), 7-9.

5. Blazevich, A. (2007). Sports Biomechanics - The Basics: Optimising Human Performance. London: A\&C Black Publishers. 
6. D'Anna, C., Rio, L., Gomez, P.F. (2015). Competitive sport and self-concept in adolescent, Journal of Human Sport and Exercise, 10(1).

7. Gaetano, R., Domenico, T., Gaetano, A. (2015a. Physical activity and its relation to body and ludic expression in childhood Mediterranean. Journal of Social Sciences, 6(3).

8. Gaetano, R., Gomez, F.P., Gaetano, A., (2015b), Anxiety in the youth physical and sport activity. Mediterranean Journal of Social Sciences, 6(3).

9. Gamba, S. (1995). Quaderni di Riano, CONI FIP, vol I, Roma, Italy.

10. Hede, C., Russell, K., \& Weatherby, R. (2011). Senior Physical Education for Queensland. South Melbourne, Victoria, Australia: Oxford University Press.

11. Izzo, R., Sopranzetti, S., Altavilla, G. (2015). Biomechanical analysis of fundamentals in basketball the rebound, Ovidius university annals series. Physical Education and Sport, 15(2).

12. Mondoni, M. (2002) Basket e biomeccanica, Edizioni Libreria dello sport, Milano, Italia.

13. Picasso, B. (2012) Fondamenti di meccanica e biomeccanica", Ed. Springer - Milano, Italia.

14. Polidoro, L., Bianchi, F., Di Tore, P. A., Raiola, G. (2013). Futsal training by video analysis. Journal of Human Sport and Exercise, 8, (2).

15. Napolitano, S., Tursi, D., Raiola, G. (2013). Waterpolo women's pattern tactical experience of an Italian team. Journal of Human Sport and Exercise, 8(3).

16. Raiola, G. (2015a). Sport skills and mental health. Journal of Human Sport and Exercise, 10, 1 supplement.

17. Raiola, G., (2015b). Basketball feint and non-verbal communication: empirical framework. Journal of Human Sport and Exercise, 10, 1 supplement.

18. Raiola, G. (2014). Motor control and learning skills according to cognitive and ecological dynamic approach in a vision on behaviorism, cognitive, Gestalt and phenomenology theories. Mediterranean Journal of Social Sciences, 5(15).

19. Raiola, G. (2011). A study on Italian primary school rules: Neurophysiological and didactics aspects on physical education and sport. Journal of Physical Education and Sport, 11(2).

20. Raiola, G., Tafuri, D. (2015). Teaching method of physical education and sports by prescriptive or heuristic learning. Journal of Human Sport and Exercise, 10, 1 supplement.

21. Raiola, G., Lipoma, M., Tafuri, D. (2015). Postural control in young soccer players: differences between the cognitive approach and ecological-dynamic one. Journal of Human Sport and Exercise, 10, 1 supplement.

22. Raiola, G., Tafuri, D., Paloma, G. (2014). Physical activity and sport skills and its relation to mind theory on motor control. Sport Science, 7(1), 52-56.

23. Rojas, F., Cepero, M., Oña, A., \& Gutierrez, M. (2000). Kinematic adjustments in the basketball jump shot against an opponent. Ergonomics, 43 (10), 1651-1660.

24. Scrimaglio R., Di Giminiani R. (2013). Analisi cinematica e dinamica del movimento, Libreria Benedetti, L'Aquila, Italia.

25. Tursi, D., Napolitano, S., Di Tore, P.A., Raiola, G. (2013). Arm stroke: A comparative analysis between competitive swimming and water polo athletes. Journal of Human Sport and Exercise, 8(2). 